\title{
Ontomorphogenesis of some species of Hemerocallis genus in the conditions of the forest-steppe zone of the Novosibirsk region
}

\author{
Lyudmila Sedelnikova * \\ Central Siberian Botanical Garden, SB RAS, 630090 Novosibirsk, Russia
}

\begin{abstract}
Morpho-biological features of the development of 5 species of the genus Hemerocallis in the conditions of the forest-steppe zone of Western Siberia are studied. The results of ontomorphogenesis are presented. 8 ontogenetic states are described. It is noted that the pregenerative period of ontogenesis lasts 2 years. The generative period of ontogenesis occurs at 3 years in plants developed from seeds. The species specificity in the formation of generative organs in autumn $(\mathrm{H}$. minor, $\mathrm{H}$. citrina, $\mathrm{H}$. lilio-asphodelus) and the spring growth period ( $\mathrm{H}$. fulva) was establish. A palynomorphological analysis of pollen grains of 4 species $(H$. citrina, H. minor, $H$. middendorfii, $H$. fulva) was carried out. The implicitly polycentric type of biomorph is determined. Complete morphological disintegration is characteristic of underground organs. The possibility of ex situ conservation of species by seed and vegetative reproduction is noted.
\end{abstract}

\section{Introduction}

Wild species of the genus Hemerocallis L. (daylily, trout lily, Hemerocallidaceae R. Br. family) are perennial polycarpic herbaceous rhizomatous plants. Many of them are cultivated in botanical gardens in Russia and abroad. It is known that culture conditions exert impact on changes of adaptive morphobiological characters of plants. Vegetative and generative organs are the most plastic, formed under the influence of species habitat conditions [1-4]. The aim is a comparative study of the ontomorphogenesis of five four species of Hemerocallis genus in the conditions of the forest-steppe zone of Western Siberia.

\section{Material and methods}

The research is performed in the Central Siberian botanic garden of the Siberian Branch of the Russian Academy of Science (Novosibirsk). As objects of research served plants of 5 species: H. citrina Baroni, H. fulva L., H. middendorfii Trautv. et C. A. Mey., H. lilioasphodelus L. (H. flava L.), H. minor Mill. The apical zone of the monocarpic shoot was

* Corresponding author: lusedelnikova@yandex.ru 
analyzed and photographed by Carl Zeiss Stereo Discovery V 12 stereomicroscope with AxioCam MRc-5 color digital cameras of high resolution and the AxioVision 4.8 program. The pollen image was taken using a Hitachi-1000 scanning microscope. The description of ontogenesis and organogenesis was made by the standard techniques [5-6].

\section{Results and discussion}

Daylilies grow at the transition of stable temperatures through $+5{ }^{\circ} \mathrm{C}$, less often at $+10{ }^{\circ} \mathrm{C}$ (the end of the third decade of April, the first decade of May) in the conditions of the foreststeppe zone of Western Siberia (south of Novosibirsk). The leaves of the studied species were root, linear, sharp at their top, plain, with outstanding ribs, arcuate. The color of lamina varies from light green $(H$. fulva, $H$. minor, $H$. citrina) to dark green $(H$. middendorfii). Species differ on their leaves width, among increase in width daylilies were ranked as follows: H. minor $(0.7-1 \mathrm{~cm}), H$. citrina $(1.8-2.2 \mathrm{~cm}), H$. middendorfii $(2.5-3$ $\mathrm{cm})$, H. fulva $(3-3.5 \mathrm{~cm})$. Its duration is 25-35 days.

The study of the ontogenesis of $H$. minor, H. citrina, $H$. lilio-asphodelus showed that the latent period $(s e)$ in seeds is characterized by a short rest. The type of seed germination is underground. The duration of the seedling $(p)$ is 15-25 days. In the phase of development of the second leaf, the brush-root system is formed. A juvenile $(j)$ age-related condition occurs. Its duration is 25-35 days.

The immature $(\mathrm{im})$ age state is characterized by the presence of a developmental phase of $3-5$ leaves in an individual. A small rhizome with a powerful root system is formed in the basal part of the shoot. The duration of the immature state is 30-40 days. By autumn, the plants pass into winter rest. In the second year, only vegetative shoots of 2-3 pieces $(H$. citrina, H. lilio-asphodelus), 3-5 pieces (H. minor) are formed in virginal ( $v$ ) individuals. The length of the vegetative shoots was $15-25 \mathrm{~cm}$. The pregenerative period (V) in the daylilies lasts for two years (Fig. 1).

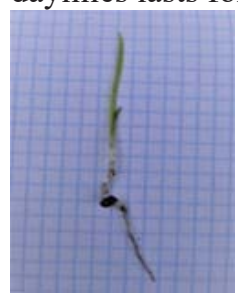

$p$

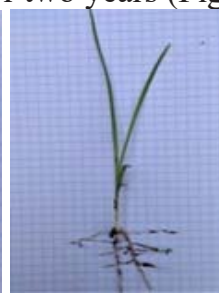

$j$

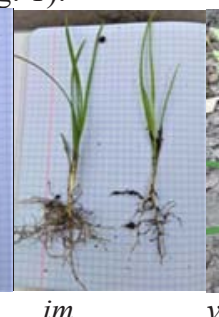

im

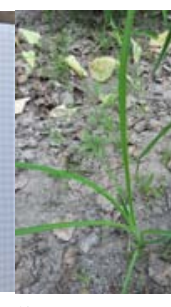

$v$

Fig. 1. Ontogenetic states of $H$. lilio-asphodelus individuals

Note: $p$-seedling; $j$ - juvenile; $i m$ - immature; $v$ - virginal; $g_{1}$-young generative; $g_{2}$ - middle-aged generative

In the third year, the generative period $(\mathrm{G})$ began, which is characterized by a young $\left(g_{1}\right)$ state. The fourth year of plant life is characterized by an average age $\left(g_{2}\right)$ and the fifth year of a mature state $\left(g_{3}\right)$ of plants with a well-developed generative shoot $(82-90 \mathrm{~cm}$ in length). Generative shoots in H. minor, H. citrina, H. lilio-asphodelus, H. middendorfii are formed annually and their laying (III - IV stages of organogenesis) occurs in the pre-winter (II - III decades of September), which is characteristic of the latent-generative state $\left(g_{o}\right)$. In these species, the rudimentary organs of the flower (petals, stamens, ovary) continue to form in the spring, which corresponds to the V - VII stages of organogenesis. It is noted that the renewal shoot in H. fulva is in a vegetative state in the autumn, at the II stage of organogenesis. Only in the spring of the following year, generative organs are formed in it, which corresponds to the beginning of the III stage of organogenesis (Fig. 2). 


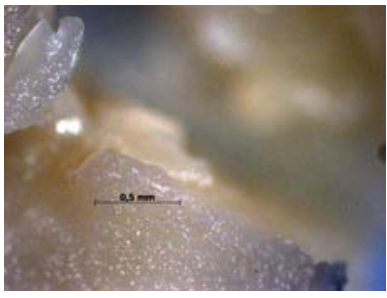

H.fulva (stage II)

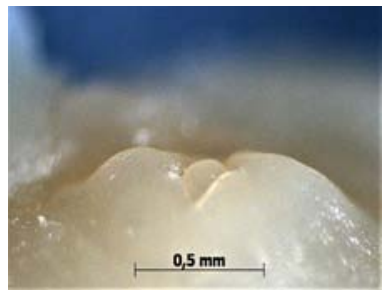

H. citrina (stages III - IV)

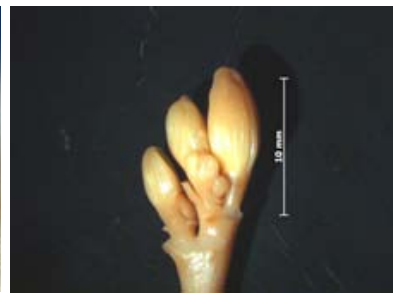

H. minor (stages $\mathrm{V}-\mathrm{VI})$

Fig. 2. Stages of organogenesis of Hemerocallis

The underground organs of the Hemerocallis are represented by a rhizome with subordinate roots (15-25 cm in length). The species have an underground compact shortbranched rhizome. Adventitious roots are mochkovatye, cord - shaped, with thickened pineal formations (root cones). According to the functions performed, the roots of daylilies can be divided into suction, storage and contractile. The origin of the rhizome in species is hypogeogenic, that is, it initially develops as an underground modified shoot. An orthotropic type of underground escape has been established. A dense arrangement of daughter rhizomes was noted in H. middendorfii and H. fulva, and in H. citrina and loose was noted in $H$. minor. The implicitly polycentric type of biomorph for the studied species was determined. Complete morphological disintegration of underground organs is characteristic. Moreover, for $H$. middendorfii, it is defined as non-specialized, since individuals of this species are vegetatively immobile. In H. citrina, H. minor, it is defined as specialized with a relatively mobile underground vegetative system, which was noted earlier [7]. Among the studied species, H. fulva is characterized by the greatest mobility of the vegetative system, since it has long plagiotropic shoots (Fig. 3).

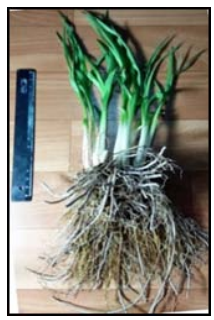

H. citrina

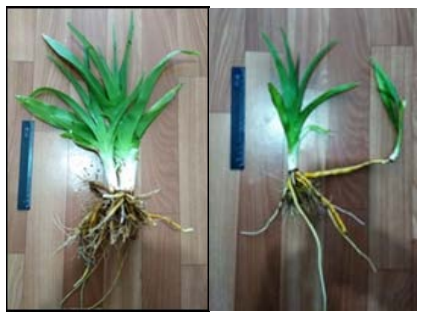

H. fulva

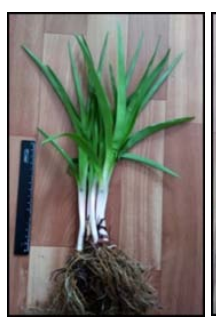

H. middendorfii

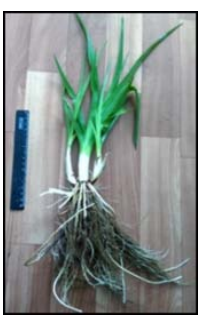

H. minor

Fig. 3. Aboveground and underground shoots of Hemerocallis

Two types of aboveground shoots: vegetative and generative are formed in Hemerocallis. Flowering of early-flowering species H. middendorfii, H. minor, H. lilioasphodelus was noted from 31.05 to $29.06, H$. citrina by 20.07 , summer-flowering species H. fulva from 15.07 to 27.08 was noted (Fig. 4).

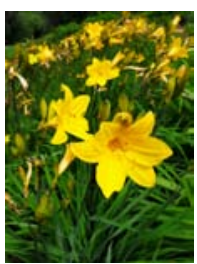

H. minor

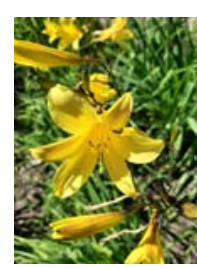

H. citrina

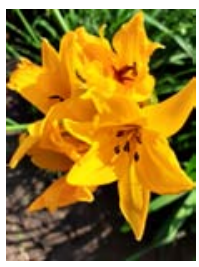

H. middendorfii

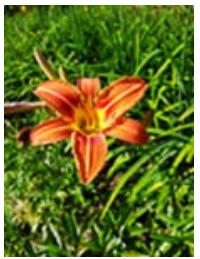

H. fulva

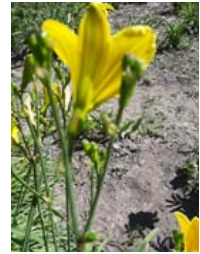

H. lilio-asphodelus

Fig. 4. The flowering of Hemerocallis in the conditions of Novosibirsk. 
The structure of pollen was studied. Pollen grains in the flowers of the studied species are heteropolar. Their poles are morphologically different from each other. The grains are ellipsoid in shape. The exina is reticulated. The pollen aperture is simple. It represents elongated sections of the exina located meridionally, in which the ratio of length to width is $>2$. They are covered with a thin elastic film (furrow membrane), which can be smooth or have a sculpture similar to the sculpture of the general surface of the pollen grain. Daylilies have single-bored pollen grains, the furrows are usually located on the distal surface (Fig. $5)$. The viability of pollen in a flower on a medium of $1 \%$ agar $+15 \%$ sucrose was determined. Pollen viability in $H$. citrina was $1.9 \%, H$. fulva $-3.3 \%$, H. lilio-asphodelus $4.1 \%, H$. middendorfii $-4.5 \%$.

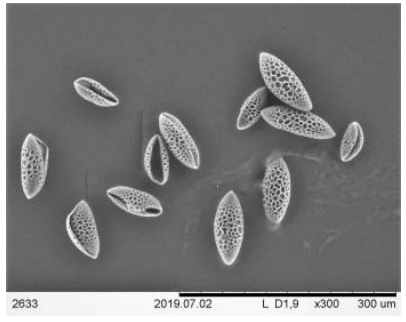

H. citrina

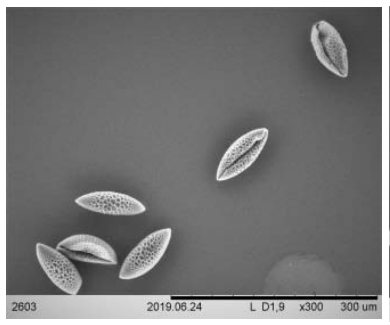

H. middendorfii

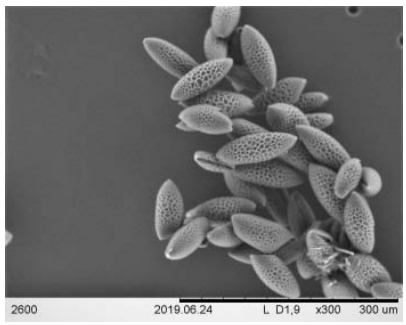

H. minor

Fig. 5. Morphology of pollen grains of some Hemerocallis species

\section{Conclusion}

The duration of the pregenerative period in daylilies is two years. The generative period begins in the third year of plant development from seeds. Generative organs are laid in autumn in early-flowering species ( $H$. citrina, $H$. minor, $H$. middendorfii, $H$. lilioasphodelus) and in spring in the summer-flowering species $H$. fulva, which is associated with the origin, contributes to the plasticity and well-expressed adaptation of the studied species to conditions of the forest-steppe zone of Western Siberia. Complete morphological disintegration is characteristic of underground organs. The species reproduce well vegetatively and partially by seeds.

This work is performed within the state task of the Central Siberian Botanic Garden of the Siberian Branch of the Russian Academy of Science on the project № AAAA-A21-121011290025-2 "Analysis of biodiversity, conservation and restoration of rare and resource plant species using experimental methods". During the preparation for the publishing there were used materials of the CSBS Siberian Branch of the Russian Academy of Science bioresource scientific collection "Collections of live plants on the field and glass-covered ground", UNU № USU 440534.

\section{References}

1. W.B. Zomlefer, Harvard Papers in Botany 3, 123 (1998)

2. L.F. Hen, P.D., Jiang, Y. Wang, H.Z. Liu, Northern Horticulture 23, 71 (2011)

3. C.Y. Zhou, M. Nie, C.D. Yang, Journal of Yangtze University (Natural Science Edition) 3, 44 (2012)

4. I.I. Krokhmal, Ecology and Noospherology 23, 41 (2012)

5. F.M. Kuperman, Plant morphophysiology (High School, Moscow, 1977)

6. P.Yu. Zhmylev, Yu.E. Alekseev, E.A. Karpukhina, Basic terms and concepts of modern plant biomorphology (Moscow State University, Moscow, 1993)

7. L.L. Sedelnikova, Vestnik KGAU 7, 55 (2016) 